\title{
Meeting the Publishing Needs of the Bioethics Community
}

\author{
Graeme T. Laurie ${ }^{1}$
}

Published online: 17 June 2021

() National University of Singapore and Springer Nature Singapore Pte Ltd. 2021

The current editorial team of the Asian Bioethics Review has now been in post for 18 months. In that time, we have worked hard to build on the existing strengths of the journal and we know that there is still much to do to realise its potential in the field of bioethics publishing. As well as reaffirming the core commitment to promote collaborative research among scholars in Asia or with an interest in Asia, and in supporting multi-cultural and multi-disciplinary bioethical studies more generally, we have sought to respond rapidly to emerging challenges in bioethics. This has been demonstrated by our 2020 Call of Papers on COVID-19 in which we guaranteed feedback within 30 days of submission. We have extended these efforts to our review processes more generally, reducing our time to first editorial decision to 58 days in 2020, down from 137 days in the previous year. At the same time, we have remained conscious of the need to continue to support scholarship in bioethics more widely, as illustrated by our Special Issue in March of this year on Reproduction, Demography and Cultural Anxieties in India and China (https://link.springer.com/journal/41649/ volumes-and-issues/13-1), and also by the diverse range of papers in this current issue on which further comment is offered below.

The lessons learned have led us to a period of reflection on how best to meet the ongoing publishing needs of the bioethics community. It seems to us that colleagues need and deserve support in two broad categories: (i) substantive and (ii) procedural support.

\section{Substantive Support}

As to substantive support, the journal provides a forum that welcomes contributions across a very broad range of types of scholarship on bioethical issues in biomedicine, healthcare, caregiving and patient support, genetics, law and governance, health systems and policy, science studies, empirical studies, recent changes in biomedical law and policy, developments in capacity building and professional training. We are particularly keen to publish work from early career scholars who will

Graeme T. Laurie

graeme.laurie@ed.ac.uk

1 Edinburgh Law School, The University of Edinburgh, Edinburgh, UK 
benefit from additional input from the editorial team in shaping their contribution and core messages. As to empirical studies, readers can find a wealth of qualitative data across many of our issues, supporting deep bioethical reflection on the implications of these data for policy and wider society. This having been said, an important point for future empirical authors to note is that there is always the need for a strong bioethical underpinning in the analysis of their data. We signal this here as a general comment, and we always provide specific feedback on individual empirical submissions.

\section{In This Issue}

The contributions in this current issue are a testament to the breadth of coverage to which the journal is committed. Thus, the article by Siraj (https://link.springer.com/ article/10.1007/s41649-021-00170-6) on the working of the Human Organ Transplantation Act in Bangladesh is a good illustration of how to bring values-based analysis to law. In this example, an account is given of the Bangladeshi legal framework that was implemented in 1999 and recently reformed in 2018 to extend the living donor pool from immediate family to more extended family members. The analysis that is offered explores how far the law reform reflects the teachings of the Quran that encourage Muslims to be sympathetic to any member of humanity but recognises the particular value of saving the life of a family member. The paper also offers insights into the ethical dilemmas that arise from incentive schemes to donate, especially relating to support of post-operative care (or the lack thereof).

The paper by Amin et al. (https://link.springer.com/article/10.1007/s41649-02100171-5) explores the ethics and governance of the MyCohort Project in Malaysia that was established in 2005, and which now represents the largest and most comprehensive resource of its kind in the country. This involves hundreds of thousands of human samples stored for research. The phenomenon of biobanking on this scale is now over two decades old, but the contribution of this paper-a particular focus for which the journal provides an outlet-is to juxtapose the experiences in Malaysia against the extensive discussions on biobanking in other countries and regions. Thus, while the ethical issues relating to biobanking are by now well-rehearsed, this paper nonetheless provides important insights from the Malaysian perspective, including the need for more empirical work on the nature and extent of public understanding and acceptance; the importance of monitoring changes in attitude over time; evaluating the robustness of the existing legal and governance frameworks relative to the ethical values and interests at stake; assessing the fitness-for-purpose of consent for Malaysian participants; capturing and reflecting religious views and values as part of a well-functioning governance framework; and monitoring levels of public trust in the entire endeavour. These experiences and recommendations are self-evidently not only of relevance to Malaysia but to all stakeholders involved in the enterprise of biobanking. The call for more empirical work exploring extant ethical issues is precisely the kind of work that the Asian Bioethics Review seeks to support as part of its comprehensive undertaking to the bioethics publishing world. 
In stark contrast to the previous two papers, the paper by Simkulet (https://link. springer.com/article/10.1007/s41649-021-00176-0) does not offer any particular insights from or about Asia. It is not designed to do so. Rather, it is a further illustration of the broad spectrum of bioethics scholarship that this journal seeks to support, including papers from all countries and with value to multi-cultural bioethical studies. In this article, Simkulet examines mitochondrial replacement techniques (MRTs) as these potentially implicate the classic non-identity problem in philosophy. The paper is valuable for its review of several attempts to address the problem and it is novel in its proposal of a solution. By these means, the journal is delighted to contribute to a long-standing debate in the field.

The final Original Article in this issue brings us back to the current pandemic crisis. As mentioned above and in a previous editorial, our Call for Papers on ethical responses to COVID-19 has attracted a wealth of scholarship that has been supported through rapid review and turnaround in the quality assurance process. Two broad types of paper have emerged from this call. The first relates to capturing the experiences of different countries - in Asia and beyond-in attempting to handle the worst vagaries of the pandemic. We believe that the journal provides an excellent evidence base in this regard, albeit that this will doubtless need to be extended as subsequent waves engulf countries and their strategies have to adapt. Secondly, we have a set of papers of which the contribution by Chan (https://link.springer.com/article/10.1007/s41649-021-00174-2) is an example: these are papers that ask questions about the core ethical values and concepts that are implicated by the advent of the pandemic and how bioethics might help to craft novel ways to address the same. In this particular article, Chan examines the possible role of reciprocal trust in designing and delivering effective COVID-19 responses. Defined as '...the trust that results when a party observes the actions of another and reconsiders one's trust-related attitudes and subsequent behaviours based on those observations', reciprocal trust is developed as a concept in this paper drawing on the experiences of South Korea and Taiwan as instances of this kind of trust in action. A synthesis approach is offered to learn lessons from these distinct experiences, and a defence is mounted as to how a greater commitment to reciprocal trust might be a way to reconcile better the need for on-going restrictive social measures with the due protection of individual freedoms and rights.

The last paper in this issue is an example of a Perspective Article. This type of contribution has long been supported by the journal as a shorter publication that offers insights of individuals gained through analyses or critical reflection of past or present developments or experiences or reports from organisations on their bioethical policies and practices. In the current instance, we re-published herewith minor amendments - a paper by Matsui et al. (https://link.springer.com/artic le/10.1007/s41649-021-00178-y) that was originally published in Japanese, and which proposes a model of core competencies for research ethics consultants. This service is reminiscent of clinical ethics consults prevalent in the USA but novel for its focus on research ethics; the comparative value of the paper is therefore self-evident beyond its own independent worth. Moreover, this kind of contribution reflects the journal's commitment to capturing and demonstrating the value of bioethics in action both for professional training and capacity building. 


\section{Procedural Support}

Each of the above papers has benefitted from substantive support from the infrastructure that the Asian Bioethics Review provides. We believe that these kinds of contributions - complemented by those listed above-should continue to typify the inclusive tenet of the journal in supporting a wide range of diverse outputs from the bioethics community. Beyond this, however, there are also a number of procedural ways in which the journal contributes to a better experience for authors. These include the following:

- Rapid decisions on reject or proceed - always supported with full explanation

- A transfer desk facility to help find a better home for rejected papers within the Springer Nature family of journals

- An author tracking service whereby the stages of review can be followed

- A commitment to keeping final decision times to a minimum

- Format-free submissions - a new feature will soon be introduced allowing authors to submit papers in the format of their choice for review purposes. Journal formatting will then only be required on acceptance.

\section{Next Steps}

We invite suggestions from authors-existing and future-as to how we can continue to improve the journal. Notably, we are currently reviewing our editorial policy on the types of articles that we publish. While Perspective Articles have had their place, we are not convinced that the length of a piece is necessarily linked to quality or originality. It can do a disservice to an article not to be categorised as an Original Article. Accordingly, we are contemplating moving to a more streamlined approach whereby all papers that demonstrate sufficient originality and significance will be published as original articles, up to a maximum of 8000 words. Longer pieces that merit further in-depth analysis will be considered on an individual basis.

We invite feedback from our readership on these proposals and on any other matter relating to the service that we offer to the bioethics community. Suggestions can be sent toABR@NUS.EDU.SG.

Publisher's Note Springer Nature remains neutral with regard to jurisdictional claims in published maps and institutional affiliations. 